\title{
As incertezas da pandemia: a experiência da covid-19 no Rio Grande do Sul*
}

\author{
The uncertainties of the pandemic: \\ the covid-19 experience in Rio Grande do Sul state
}

\footnotetext{
Beatriz Teixeira Weberi

i Professora, Programa de Pósgraduação em História/Universidade Federal de Santa Maria. Santa Maria - RS - Brasil orcid.org/0000-0003-0775-9928 beatriztweber@gmail.com

Recebido em 4 set. 2020. Aprovado em 14 maio 2021.
}

WEBER, Beatriz Teixeira. As incertezas da pandemia: a experiência da covid-19 no Rio Grande do Sul. História, Ciências, Saúde - Manguinhos, Rio de Janeiro, v.29, n.1, jan.-mar. 2022, p.277-282.

\section{Resumo}

Apresenta o quadro de incertezas nas medidas adotadas no Rio Grande do Sul sobre o SARS-CoV-2 em 2020, ressaltando a importância da pesquisa das ciências humanas para a interpretação dos significados da pandemia. Palavras-chave: coronavírus, pandemia, Rio Grande do Sul.

\section{Abstract}

It presents the uncertainties on decisions about SARS-CoV-2 taken by Rio Grande do Sul state in 2020, stressing the importance of human sciences in the interpretation of the meanings of the pandemic.

Keywords: coronavirus; pandemic; Rio Grande do Sul. 
U m cidadão da cidade de Taquara, próxima a Porto Alegre, morreu com hemorragia nasal em 18 de novembro de 1918, quando uma "mosca-varejeira" teria "depositado micróbios" no nariz, machucado por causa da "influenza", morrendo com uma "bicheira" no cérebro. Outros relatos no mesmo periódico informam que a febre da gripe provocava delírios, o que teria feito uma senhora atirar-se em um rio e outra em um poço. Todos são casos relatados como mortes em consequência da gripe publicados no jornal Gazeta do Povo, de Porto Alegre (Weber, 1999, p.64). São tentativas de informar sobre a chamada "gripe espanhola" de 1918, num contexto de quase total ignorância sobre o problema enfrentado (Abraão, 1998). Esses relatos, assim como outros que os historiadores trouxeram à baila com suas pesquisas sobre a pandemia de influenza em 1918, demonstram o quadro de incerteza vivido em outro momento. O desconhecimento da situação faz com as pessoas pensem a partir do conhecimento que já possuem, articulando informações de outras situações para a doença específica que estiver em evidência no momento. Também vivemos outra situação de insegurança hoje, setembro de 2020, numa experiência que tem deixado todos os envolvidos numa angústia constante com a pandemia, enfrentando desafios em uma situação que se altera todos os dias.

Numa das poucas certezas de hoje, acredito que as ciências humanas possuem uma contribuição importante para a compreensão das doenças e do modo como afetam os grupos envolvidos. As pesquisas sobre a gripe de 1918 oferecem várias possibilidades de compreensão do fenômeno que uma pandemia representa, chegando até a sugerir procedimentos. Um dos exemplos é a pesquisa de uma equipe que examinou a implementação de intervenções não farmacêuticas para mitigação da epidemia da influenza nos EUA de 8 de setembro de 1918 a 22 de fevereiro de 1919. O estudo envolveu o levantamento de 43 cidades para compreender que fatores estavam associados à variação na mortalidade. As intervenções não farmacêuticas foram agrupadas em três categorias principais: fechamento de escolas, cancelamento de reuniões públicas, isolamento/quarentena. Os dados de mortalidade foram obtidos do Weekly Health Index do US Census Bureau para 1918-1919, relatórios que listam o total de mortes e taxas de mortalidade nos EUA. As 43 cidades estudadas eram centros urbanos populosos que tinham registros arquivísticos abrangentes, podendo ser dados jornalísticos ou registros municipais (Markel et al., 2007).

O estudo envolveu uma equipe de pesquisadores procurando relacionar fontes da época com análises estatísticas contemporâneas, visando analisar a implementação de intervenções que fazem parte dos procedimentos mais antigos e tradicionais utilizados frente a contextos epidêmicos, como isolamento, quarentena e distanciamento social. São procedimentos adotados quando não há vacina ou outros medicamentos que possam ser usados para atacar a doença, como ocorreu com a influenza no contexto de 1918. O resultado do levantamento indica que a combinação de fechamento das escolas e proibição de encontros públicos, por duração média de quatro semanas, resultou na redução da taxa de mortalidade semanal e total. E as cidades que implementaram essas intervenções mais cedo tiveram dados mais favoráveis, com menor mortalidade. As medidas de intervenção não farmacêutica retardaram os efeitos da pandemia e reduziram o número de mortos. Segundo os autores, medidas como essas podem fornecer um tempo valioso para a produção e distribuição de vacinas e medicamentos antivirais em outros contextos. A implementação de intervenções 
não farmacêuticas diminuiria a carga sobre os serviços de saúde e a infraestrutura desses serviços. O estudo é de 2007, anterior, portanto, à atual pandemia de coronavírus, mas já oferecia elementos que poderiam ajudar na análise dos procedimentos a adotar. Não temos informações se esse estudo foi utilizado para pensar as circunstâncias de 2020, mas é provável que não, apesar de o vocabulário ser tão próximo da situação que vivemos hoje, sugerindo medidas importantes para o enfrentamento de doenças desconhecidas.

Os pesquisadores que trabalham a partir de estudos sistemáticos sobre a situação da propagação de doenças têm uma contribuição indispensável na compreensão do quadro de pandemia em que estamos inseridos. No Brasil, essas pesquisas são produzidas principalmente nas universidades, que cumprem um papel importante de levantamento e análise dos dados. Elas incluem estudos clínicos, assim como estudos geográficos, sociológicos, antropológicos e históricos, além da produção de equipamentos para uso no sistema de saúde. Balanço divulgado pela Associação Nacional de Dirigentes das Instituições Federais de Ensino Superior indica que vêm sendo desenvolvidas 1.265 pesquisas específicas sobre o novo coronavírus (Andifes, 19 jun. 2020).

Inicialmente, as medidas adotadas no Rio Grande do Sul foram pensadas a partir de estudos da área de epidemiologia, realizados em instituições federais e coordenados pela Universidade Federal de Pelotas, com entrevistas e testagem de pessoas sorteadas em nove cidades. Esses estudos indicaram os procedimentos de isolamento (Rio Grande do Sul, s.d.b). Vários outros grupos de instituições públicas de ensino procuram realizar pesquisas e oferecem seus resultados ao público. É o caso do grupo da UFPel, Grupo de Estudos Covid-19: Estudos Geográficos, do Laboratório de Estudos Urbanos e Regionais da UFPel, pesquisa que permitiu compreender que ocorrem maneiras distintas de transmissão comunitária da covid-19 no estado, tendo em vista a existência de estruturas territoriais díspares entre o sul e o norte do Rio Grande do Sul no que se refere à organização dos municípios (Duarte, Vieira, 29 abr. 2020). Outro registro sistemático da pandemia ocorre na UFSM, por meio do Observatório de Informações em Saúde/UFSM, que disponibiliza dados estatísticos sobre o SARS-CoV-2 desde 2 de março de 2020, visando auxiliar no monitoramento e planejamento das ações em saúde pública para o combate da covid-19, com dados atualizados diariamente (Observatório..., s.d.). É o registro da pandemia feito por instituições públicas de ensino e pesquisa, cumprindo seu papel.

A política de enfrentamento ao coronavírus adotada pelo governo do estado do Rio Grande do Sul, em maio de 2020, foi chamada de distanciamento controlado, baseado na segmentação regional e setorial, prevendo quatro níveis de restrições, representados por bandeiras nas cores amarela, laranja, vermelha e preta, que variam conforme a propagação da doença e a capacidade do sistema de saúde em cada uma das vinte regiões. Os dados das dimensões são cruzados para definir o risco epidemiológico e o nível de distanciamento exigido. As regiões foram definidas a partir dos dados, de modo que existam hospitais de referência com leitos de UTI dentro de cada área. Cada região é avaliada semanalmente por meio de 11 indicadores que levam em conta a propagação do vírus (velocidade do avanço, estágio da evolução e incidência de novos casos sobre a população) e capacidade de atendimento, calculando o grau de risco com pesos diferenciados. O risco baixo da bandeira amarela indica alta capacidade do sistema de saúde e baixa propagação da doença, ao 
contrário do risco altíssimo da bandeira preta. Majoritariamente as várias regiões variaram entre bandeira laranja e vermelha.

As medidas de distanciamento adotadas levam em conta as atividades econômicas em 12 grupos, estabelecendo medidas para cada um deles. Cada setor econômico tem critérios específicos que variam de acordo com a bandeiras. Essas medidas estabelecem regras para a maior liberação da abertura dos estabelecimentos ao público por meio de Decretos de Calamidade, portarias da Secretaria de Saúde e atos das autoridades municipais, fundamentadas nas evidências científicas e em análises sobre informações estratégias em saúde. Os protocolos obrigatórios para todas as bandeiras envolvem as regras já amplamente adotadas, como uso de máscaras, distanciamento mínimo de dois metros sem equipamentos de proteção individual (EPI) e um metro com EPI, teto de ocupação, higienização de ambientes, afastamento de casos suspeitos e atendimento para grupos de risco, entre outros.

Essas informações estão todas disponibilizadas pelo governo do estado em uma plataforma acessível (Rio Grande do Sul, s.d.a). Foi instituído um Gabinete de Crise em março de 2020, com oito comitês específicos, que se reúnem periodicamente e discutem os temas de impacto econômico, na saúde, no sistema prisional, na comunicação e em serviços digitais e de dados, com o apoio técnico de especialistas e de entidades da sociedade e do governo. Esses grupos propõem medidas conjuntas para todo o estado. Cada município nas diversas regiões deve acatar as medidas gerais e estabelecer portarias com suas próprias regras. A partir de agosto de 2020, houve a possibilidade de Gestão Compartilhada do Modelo de Distanciamento Controlado. Os municípios de cada região que querem adotar protocolos distintos para as atividades elaboram planos estruturados próprios, aprovados por no mínimo $2 / 3$ dos prefeitos da região, avalizados por equipe técnica e encaminhados ao Gabinete de Crise.

Essa proposta gerou discussões constantes na reavaliação do modelo implantado, com os prefeitos de cada um dos municípios realizando contestações dos dados e com os representantes dos vários setores econômicos demandando medidas que consideravam mais ajustadas. Não há consenso. As pressões de cada setor econômico sobre as prefeituras e a visão de mundo que cada prefeito adota fazem com que a discussão e reavaliação das medidas sejam uma constante, gerando mais incertezas a cada semana. Reconhecer diferentes regiões e setores está sendo um dos desafios, para o qual não há resposta unificada. A dinâmica político-partidária, as disputas locais e regionais e os distintos interesses socioeconômicos certamente têm grande influência nas medidas adotadas pelo Estado. Mesmo assim, pode-se afirmar que a concepção do modelo de distanciamento controlado no estado do Rio Grande do Sul evidenciou a relevância da adoção de critérios concretos e mensuráveis, com base científica, para a tomada de decisões, ainda que, em diversas ocasiões, exista uma evidente discrepância entre os critérios técnicos e a sua aplicação prática. Em todo caso, é sempre pertinente remarcar a excepcionalidade do momento atual. Essa afirmação está relacionada à análise do impacto da doença nos distintos países, o seu grau de transmissibilidade, favorecido pela dinâmica global de circulação de pessoas e mercadorias, e pelo expressivo impacto econômico causado. No entanto, um dos principais aspectos que ela evidenciou foi a necessidade de ações integradas, entre pessoas, nações e instituições, como forma de dar respostas coletivas a problemas que têm um impacto coletivo. Nesse sentido, é assinalável o esforço global no desenvolvimento e na produção das vacinas, que atende a 
critérios científicos e é resultado de articulações em distintos níveis. Mesmo assim, pode-se afirmar que a falta de coordenação é um dos principais entraves para o esforço de combate à pandemia, tanto em nível global quanto na especificidade do caso brasileiro.

Há uma série de obstáculos a superar, como a adesão às medidas preventivas, limites da capacidade de testagem e o risco de sobrecarga na rede de atendimento. Os pesquisadores da história e de outras ciências sociais poderiam ajudar a trazer a análise de outros contextos, como o caso citado do estudo nos EUA, mas ainda não é um recurso no processo de compreensão das doenças. Elementos culturais fazem com que os cidadãos tenham dificuldade de entender e aceitar o isolamento como uma das medidas para evitar um caos pior, como já ocorreu em tantos outros episódios de disseminação de doenças. Há um conjunto complexo de elementos sociais e políticos. A compreensão do papel dos elementos em jogo em cada uma das situações permitiria que as medidas de políticas públicas adotadas fossem mais efetivas.

A contextualização histórica desta pandemia é fundamental para a compreensão acerca das dinâmicas que têm se produzido, sobretudo no que diz respeito à ação do Estado e à abordagem dada à doença nos meios de comunicação social e de divulgação científica. A compreensão das tradições que informam a população de cada região pode oferecer perspectivas que ajudam a entender o significado que a doença, o medo e a cura assumem para as sociedades: perspectivas religiosas, sobre o papel dos cuidadores, sobre o papel da medicina e das medidas orientadas por essa área de conhecimento. A descrição do quadro da gripe de 1918, no início deste texto, indica que as avaliações das doenças ocorrem com elementos específicos de cada grupo (Weber, 1999). O papel do historiador, e dos cientistas sociais em geral, é compreender esses significados, levando em conta o humano de forma mais integral e ampla. Nenhum fenômeno social pode ser minimizado com respostas simplificadoras. Os conceitos de saúde e de doença são históricos, os processos de adoecer e de curar são socialmente vivenciados e construídos, envolvendo todos os âmbitos das manifestações socioculturais. Para a formulação de políticas públicas mais eficazes, é fundamental que sejam baseadas no conhecimento acumulado sobre esses significados (Porter et al., 2002; Helman, 2009).

O fato de estarmos vivenciando um fenômeno global, numa situação epidêmica épica pela dimensão que assumiu e pela rapidez da propagação, não exime a necessidade de pensarmos a partir das situações de compreensão da população em que os fenômenos se inserem. A adoção de medidas de cuidado individual afeta o conjunto em que todos estão inseridos. O desafio é entender como as pessoas reagem ao medo da doença, à disseminação de informações falsas, como os indivíduos recebem e processam as informações, fazendo com que compartilhem ou não procedimentos considerados mais convenientes. Vários estudos da história nos ajudam a compreender como as doenças foram sendo apropriadas de forma diferente, gerando disputas sobre as medidas adotadas. É o campo de compreensão das vacinas, que possui uma longa história de apropriações diferentes, que a historiografia mais recente procura abordar (Chalhoub, 1996; Chalhoub et al., 2003; Pôrto, Ponte, 2003). Somente o estudo da configuração dessas áreas vai permitir entender e adotar estratégias.

Não há respostas prontas, é preciso estudo sistemático, principalmente em contextos de ignorância. As pesquisas organizadas podem oferecer algumas respostas, mesmo com 
as incertezas, que também fazem parte da produção do conhecimento. Para superar a incerteza, o investimento na pesquisa precisa ser permanente. Somente isso poderá oferecer procedimentos mais viáveis.

\section{NOTA}

* O presente texto é uma versão mais completa, atualizada e submetida a revisão por pares de uma postagem veiculada no blog de História, Ciências, Saúde - Manguinhos.

\section{REFERÊNCIAS}

ABRAÃO, Janete. Banalização da morte na cidade calada: a hespanhola em Porto Alegre, 1918. Porto Alegre: EDIPUCRS, 1998.

ANDIFES, Associação Nacional de Dirigentes das Instituições Federais de Ensino Superior. I Congresso Andifes destaca ações das universidades federais no combate ao coronavírus, 19 jun. 2020. Disponível em: http://www.andifes.org.br/i-congresso-andifesdestaca-acoes-das-universidades-federais-nocombate-ao-coronavirus. Acesso em: 4 set. 2020 .

CHALHOUB, Sidney. Cidade febril: cortiços e epidemias na corte imperial. São Paulo: Companhia das Letras, 1996.

CHALHOUB, Sidney et al. Artes e ofícios de curar no Brasil: capítulos de história social. Campinas: Editora da Unicamp, 2003.

DUARTE, Tiaraju Salini; VIEIRA, Sidney Gonçalves. Grupo de pesquisa Covid-19/ Estudos Geográficos/LEUR/UFPel realiza mapeamento dos casos confirmados da Covid-19 e das estruturas de saúde na região Sul-RS, 29 abr. 2020. Disponível em: https://wp.ufpel. edu.br/cidadeecidadania/2020/04/29/grupode-pesquisa-covid-19-estudos-geograficosleur-ufpel-realiza-mapeamento-dos-casosconfirmados-da-covid-19-e-das-estruturas-desaude-na-regiao-sul-rs/. Acesso em: 4 set. 2020.
HELMAN, Cecil G. Cultura, saúde e doença. Porto Alegre: Artmed, 2009.

MARKEL, Howard et al. Nonpharmaceutical interventions implemented by US cities during the 1918-1919 influenza pandemic. JAMA, v.298, n.6, p.644-655, 2007. Disponível em: https:// jamanetwork.com. Acesso em: 25 abr 2021.

OBSERVATÓRIO de Informações em Saúde, s.d. Disponível em: https://www.ufsm.br/ coronavirus/observatorio. Acesso em: 4 set. 2020.

PORTER, Roy et al. Medicina: a história da cura das antigas tradições às práticas modernas. Lisboa: Livros e Livros, 2002.

PÔRTO, Angela, PONTE, Carlos Fidelis. Vacinas e campanhas: imagens de uma história a ser contada. História, Ciências, Saúde - Manguinhos, v.10, supl.2, p.725-742, 2003.

RIO GRANDE DO SUL. Coronavírus, s.d.a. Disponível em: https://coronavirus.rs.gov.br/ inicial. Acesso em: 4 set. 2020.

RIO GRANDE DO SUL. Pesquisa de prevalência, s.d.b. Disponível em: https://www.estado. rs.gov.br/estudo-epidemiologico-pesquisa-deprevalencia. Acesso em: 4 set. 2020.

WEBER, Beatriz Teixeira. As artes de curar: medicina, religião, magia e positivismo na República Rio-Grandense, 1889-1928. Santa Maria/Bauru: Ed. da UFSM/EDUSC, 1999. 